\title{
Separation and isolation of tautomers of 2-hydroxy-4-naphthoquinone-1-oxime derivatives by liquid chromatography: Antiproliferative activity and DFT studies
}

\author{
YOGESH SHINDE ${ }^{\mathrm{a}}$, STEPHEN SPROULES ${ }^{\mathrm{b}}$, LAXMI KATHAWATE ${ }^{\mathrm{a}}$, SANJIMA PAL ${ }^{\mathrm{c}}$, \\ V BADIREENATH KONKIMALLA ${ }^{\mathrm{c}}$ and SUNITA SALUNKE-GAWALI ${ }^{\mathrm{a}, *}$ \\ ${ }^{a}$ Department of Chemistry, University of Pune, Pune 411 007, India \\ ${ }^{b}$ WestCHEM, School of Chemistry, University of Glasgow, Glasgow G12 8QQ, UK \\ ${ }^{c}$ School of Biological Sciences, National Institute of Science Education and Research (NISER), \\ Bhubaneswar 751 005, India \\ e-mail: sunitas@chem.unipune.ac.in
}

MS received 21 May 2013; revised 21 October 2013; accepted 31 October 2013

\begin{abstract}
Reversed phase HPLC separation and isolation of isomers of 2-hydroxy-4-naphthoquinone-1oxime (Lwox) and 3-methyl-2-hydroxy-4-naphthoquinone-1-oxime (Phox) have been investigated. Two distinct peaks are observed in the chromatogram of Lwox and are assigned to 'para' tautomer; 2-hydroxy-4naphthoquinone-1-oxime (3) and 'ortho' tautomer; 4-hydroxy-2-naphthoquinone-1-oxime (4). The tautomeric equilibrium of $\mathbf{3}$ and $\mathbf{4}$ has been manipulated by incrementally increasing the $\mathrm{pH}$ of the mobile phase from 2.5 to 10.5 , and altering the solvent polarity. At $\mathrm{pH}>6.8$ the tautomers are well-separated from each other. There is no separation of Phox isomers between $\mathrm{pH} 2.5$ and 10.5. Isolation of the tautomers has been carried out by preparative HPLC, with $\mathbf{3}$ and $\mathbf{4}$ obtained as ammonium bicarbonate adducts and characterized by LC-MS, FTIR, and UV-visible spectroscopy. Red-orange 3 is characterized by a paranaphthoquinone stretch at $1287 \mathrm{~cm}^{-1}$ and a charge transfer band at $420 \mathrm{~nm}$; yellow 4 exhibits, a similar stretch at $1246 \mathrm{~cm}^{-1}$ and absorption band at $406 \mathrm{~nm}$. Compounds 3 and $\mathbf{4}$ were screened for selective antiproliferative activity in three cancer cell lines of different tissue types (COLO 205 (human colorectal adenocarcinoma), U87 MG (glioblastoma astrocytoma) and MIAPaCa-2 (human pancreatic carcinoma). Geometry-optimized structures for tautomers $\mathbf{3}$ and $\mathbf{4}\left(\mathbf{3}^{\prime}\right.$ and $\mathbf{4}^{\prime}$ in Phox) were computed using the B3LYP method. Structures, 3 and $\mathbf{3}^{\prime}$ are 4.7 and $5.8 \mathrm{kcal} \mathrm{mol}^{-1}$ more stabilized than $\mathbf{4}$ and $\mathbf{4}^{\prime}$, respectively, as a result of a hydrogen bond interaction between the 2-hydroxyl group and the nitrogen of the oxime.
\end{abstract}

Keywords. Naphthoquinoneoximes; tautomer; reversed phase separation; DFT; naphthoquinone; HPLC.

\section{Introduction}

1,2-Benzoquinone monooximes, 1,2-naphthoquinone monooxime (nitrosonaphthol) and 1,2-anthroquinone oxime show tautomeric equillibria in solution between nitroso and oxime form. In 1,2-benzoquinoneoximes, the nitroso tautomeric form is more stable, ${ }^{1}$ while in 1,2-naphthoquinoneoximes, oxime form is more stable. ${ }^{2}$ The tautomeric forms of 1 and 2-nitrosonaphthols have been extensively studied by spectroscopic techniques viz UV-visible, IR and NMR spectroscopy. ${ }^{3-6}$ In nitrosonaphthols, the presence of two distinct species (A and B, scheme 1) are related

*For correspondence through an intramolecular proton transfer through the existing intra molecular hydrogen bond. Oxime tautomers of $\mathrm{A}$ and $\mathrm{B}$ are more stable than nitroso form. ${ }^{2}$ According to X-ray crystal data, ${ }^{7}$ syn oxime tautomer is present in solid state. However, in solution both the oxime and nitroso tautomeric forms coexist. Experimental and theoretical results confirmed the presence of syn and anti oxime isomers in nitrosonaphthol. ${ }^{2}$ Theoretical studies on this equilibrium between the nitrosonaphthol and oxime form are concentrated on total energies of tautomers with intramolecular hydrogen bonding. ${ }^{8}$ Calculated total energies indicate that quinonoid form to be more stable by 2.68 and $2.64 \mathrm{kcal}$ $\mathrm{mol}^{-1}$ by DFT and MP2 methods, respectively. ${ }^{8}$ The barriers of tautomerization in gas phase for $\mathrm{A}$ and $\mathrm{B}$ are estimated to be 4.70 and $5.48 \mathrm{kcal} \mathrm{mol}^{-1}$, respectively. ${ }^{2}$

Stereoisomer's of hydroxy-naphthoquinoneoxime and its C3 derivatives (scheme 2), along with their 
<smiles>O=Nc1ccc2ccccc2c1O</smiles>

Tautomers of 2-nitroso-1-naphthol (A)<smiles>O=Nc1c(O)ccc2ccccc12</smiles>

Tautomers of 1-nitroso-2-naphthol (B)

Scheme 1. Tautomers of 1- and 2- nitrosonaphthols.

nitrosophenol tautomers, were defined by ${ }^{1} \mathrm{H}$ NMR spectroscopy ${ }^{9}$ and it has been confirmed that the relative abundances of syn and amphi stereoisomer's is governed by steric as well as hydrogen bonding interactions. Single crystal X-ray diffraction studies of 3-methyl-1,4-naphthoquinone-1-oxime ${ }^{10}$ and 3-halo1,4-naphthoquinone-1-oxime ${ }^{11}$ show amphi isomers as the dominant form in solid state. Vibrational frequencies of 2-hydroxy-1,4-naphthoqunone-1-oxime and its $\mathrm{C} 3$ derivatives $\left(\mathrm{CH}_{3}, \mathrm{NH}_{2}, \mathrm{Cl}, \mathrm{NO}_{2}\right)$ in keto and nitrosonaphthol are known. ${ }^{12}$ Among all derivatives (except nitro) the amphi conformer in the keto form is predicted to be most stable, which is attributed to the intramolecular hydrogen bonding. It is well-known that hydroxy naphthoquinones possess ortho and para tautomeric forms in solution. ${ }^{13,14}$

Keto-enol tautomerism in oximes has been studied by gas chromatography, ${ }^{15,16}$ however separation and isolation of these tautomeric naphthoquinoneoximes still not established. Here, we detail the separation, isolation and characterization of tautomers of 2-hydroxy4-naphthoquinone-1-oxime (Lwox) and 3-methyl-2hydroxy-4-naphthoquinone-1-oxime (Phox) shown in scheme 2. The separated tautomers 3 and $\mathbf{4}$ of Lwox were screened for anti-proliferative activity in three cancer cell lines of different tissue types (COLO 205, U87 MG and MIAPaCa-2). The optimized structures of tautomers $\mathbf{3}, \mathbf{3}^{\prime}, \mathbf{4}$ and $\mathbf{4}^{\prime}$ have been evaluated by DFT employing a dielectric continuum to model solvent effects. The calculations identify a hydrogen bond between the 2-hydroxyl (in $\mathbf{3}$ and $\mathbf{3}^{\prime}$ ) and the oxime nitrogen that stabilizes this conformation over the 4hydroxyl (i.e., 4 and $\mathbf{4}^{\prime}$ ) tautomer.<smiles>[2H]C1=C(O)/C(=N/O)c2ccccc2C(=O)/C1=C/C=C\C</smiles>

1

2<smiles>[1H]c1c([2H])c(C)c(C)c2c1C1C(=NO)COC1=C([2H])C2=O</smiles>

3 (3' in Phox)<smiles>C=CCc1c(C)c(C)c2c(c1C)C(=NO)C(=O)C(P)=C2O</smiles>

4 (4' in Phox)

$$
\begin{aligned}
& \mathbf{R}=\mathrm{H} ; \text { Lwox } \\
& \mathbf{R}=\mathrm{CH}_{3}=\text { Phox }
\end{aligned}
$$

Scheme 2. Tautomers of hydroxy-naphthoquinoneoximes.

\section{Experimental}

\subsection{Chemicals and materials}

HPLC grade $\mathrm{CH}_{3} \mathrm{CN}$ and $\mathrm{CH}_{3} \mathrm{OH}$ was obtained from Merck chemicals. $\mathrm{HCl}$, TFA, hydroxylaminehydrochloride, $\mathrm{NaOH}$, ammonia, ammonium acetate, ammonium bicarbonate, ammonium formate and formic acid have been obtained from Qualigen Chemicals, India. 3Methyl-1,4-naphthoquinone (menadione), 2-hydroxy1,4-naphthoquinone (lawsone) has been obtained from Sigma-Aldrich. Milli Q water is used wherever necessary, anhydrous methanol is prepared for synthesis of ligands. ${ }^{17}$

The starting materials, 2-hydroxy-3-methyl-1,4naphthoquinone (phthiocol) and 2-hydroxy-4-naph thoquinone-1-oxime (Lwox), 3-methyl-2-hydroxy-4naphthoquinone-1-oxime (Phox) have been prepared according to published procedures. ${ }^{10,18}$

\subsection{Apparatus}

Shimadzu, LC-2010C $\mathrm{C}_{\mathrm{HT}}$ liquid chromatograph has been used for separation of tautomers. The detector used is SPD-M20A diode array and auto sampler injection system, connected with LC-solution with a multichannel module. Shimadzu LC-8A preparative liquid chromatograph has been used for isolation of tautomers. The detector used is SPD-M20A diode array detector and a rheodyne valve manual injection system 
(5000 $\mu \mathrm{L}$ loop), connected with LC-Solution with a multi-channel module.

Liquid chromatograph mass spectrums were recorded on Shimadzu, LCMS-2010EVwith ESI source has been used for ionization. FT-IR spectra's was recorded on a SHIMADZU FT 8400 spectrometer in KBr pellets.

\subsection{Chromatography}

An YMC ODS-A C18 and X-bridge C18 column [length $=150 \mathrm{~mm}$, internal diameter $=4.6 \mathrm{~mm}$, particle size $=5 \mu \mathrm{m}$, pore size $=12 \mathrm{~nm}$ ] has been used for separation of tautomers. A YMC-ODS C18 column $[$ length $=500 \mathrm{~mm} \times 30 \mathrm{~mm}$, particle size $=10 \mu \mathrm{m}]$ has been used for isolation of tautomers. The mobile phase consisted of water: acetonitrile in various proportions. Water and acetonitrile is always acidified with trifluoroacetic acid (TFA), mixture of ammonium formate and formic acid, basified by using ammonium bicarbonate, mixture of ammonium formate and ammonia. Ammonium acetate is used for preparation of neutral mobile phase. Detector was set at $254 \mathrm{~nm}$.

\subsection{Separation and isolation of tautomers}

Following experimental conditions are used for separation and isolation of naphthoquinoneoxime derivatives. Method I to method VII has been used for separation of isomers/tautomers. Method VIII is used for isolation of isomers of Lwox respectively. Method IX has been used for LC-MS analysis of Lwox (see Supplementary information).

\subsection{Sample preparation}

500 ppm and 5000 ppm solution of Lwox and Phox has been prepared in methanol for separation and isolation, respectively of tautomers.

\subsection{Cell lines}

COLO205 (human colorectal adenocarcinoma), U87MG (human primary glioblastoma) and MiaPaCa-2 (human pancreatic carcinoma) cell lines were obtained from National Centre for Cell Science (Pune, India). COLO205 cell line was cultured routinely in RPMI1640 medium (HiMedia, India) while U87MG and MIAPaCa-2 in DMEM media. Both medias were supplemented with $2 \mathrm{mM}$ glutamine (HiMedia, India), antibiotics $(100 \mathrm{U} / \mathrm{mL}$ penicillin A and $100 \mathrm{U} / \mathrm{mL}$ streptomycin; HiMedia, India) and $10 \%$ heat-inactivated fetal bovine serum (HiMedia, India). All cell lines were cultured in $25 \mathrm{~cm}^{2}$ flasks with loosened caps and incubated in humidified air containing $5 \% \mathrm{CO}_{2}$ at $37^{\circ} \mathrm{C}$.

\subsection{Antiproliferative activity studies}

The effect of isolated tautomer $\mathbf{3}$ and $\mathbf{4}$ on the viability of the cell lines were measured using XTT assay. The antiproliferative activity was evaluated based on the amount of 2,3-bis[2-methoxy-4-nitro-5-sulphophenyl]$2 \mathrm{H}$-tetrazolium-5-carboxanilide inner salt formed by the viable cells in the treated wells. Fresh stock solutions of $\mathbf{3}$ and $\mathbf{4}$ were prepared in DMSO at a concentration of $100 \mathrm{mM}$. Serial dilution in 50:50 media: DMSO mixtures produced stock solutions of compounds ranging from $10^{-8} \mathrm{M}$ to $10^{-4} \mathrm{M}$. About $50 \mu \mathrm{L}$ of the cell suspension diluted to a final density of $1 \times 10^{5}$ cells $/ \mathrm{mL}$ were sowed into each well of a 96-well culture plate (Axygen, USA) and treated with the varying concentrations of compounds in duplicates. The 96-well plates were left for incubation with compounds at $37^{\circ} \mathrm{C}, 5 \%$ $\mathrm{CO}_{2}$ in humidified atmosphere for $72 \mathrm{~h}$. XTT reagent was freshly prepared with XTT-labelling reagent and electron-coupling reagent in a ratio of 50:1. After $72 \mathrm{~h}$ of incubation, $50 \mu \mathrm{L}$ of this mixture was added to each of the 96 wells. The plates were incubated at $37^{\circ} \mathrm{C}, 5 \%$ $\mathrm{CO}_{2}$ in humidified atmosphere and read out after optimal colour development in each of the wells. Quantification of cell viability was performed in an ELISA plate reader (Bio-Rad, München, Germany) at $490 \mathrm{~nm}$ with a reference wavelength of $655 \mathrm{~nm}$. The above-mentioned cell lines treated with doxorubicin served as a positive control for cytotoxicity and to evaluate the same. ${ }^{19}$ OriginPro software and MS-Excel were used for data analysis and determination of $\mathrm{IC}_{50}$ value.

\subsection{DFT calculations}

All DFT calculations were performed with the ORCA program. ${ }^{20}$ Geometry optimized structures of $\mathbf{3}$ and $4\left(3^{\prime}\right.$ and $4^{\prime}$ in Phox) were achieved using the B3LYP method. $^{21,22}$ The conductor-like screening model (COSMO) was applied using water as the solvent. ${ }^{23}$ The all-electron basis sets of triple- $\zeta$ quality were those developed by the Ahlrichs group. ${ }^{24,25}$ Auxiliary basis sets were used to expand the electron density in the calculations were chosen to match the orbital basis. Geometry search was carried out in redundant internal coordinates without imposing geometrical constraints, and stationary points were characterized via analytical frequency calculations. 


\section{Result and discussion}

\subsection{Separation of 2-hydroxy-4-naphthoquinone-1- oxime (Lwox) isomers}

Separation of Lwox isomers was achieved varying the $\mathrm{pH}$ of the mobile phase using appropriate buffer solutions. Chromatographic separation is based on gradient elution. Figure 1 shows a chromatogram of Lwox separation obtained at $\mathrm{pH} 7$ (without modifier), 2.5, $4.5,6.8,8.5$ and 10.5 of mobile phase with chromatographic data is summarized in table S1. (i) At $\mathrm{pH} 7$, it has been observed that there is no interaction of Lwox (figure 1a) with mobile phase as well as stationary phase, Lwox retains in the column, moreover this $\mathrm{pH}$ is not suitable for the separation and elution of isomers/tautomers. Either Lwox is unstable in solution or there may be fast inter conversion of isomers at $\mathrm{pH} 7$. (ii) At $\mathrm{pH} 2.5$ and 4.5 (figure $1 \mathrm{~b}$ and c) peak shapes is similar to equilibrium of the isomers. ${ }^{26}$ There is no separation observed between the isomers/tautomers at this $\mathrm{pH}$. (iii) At $\mathrm{pH} 6.8$ of the mobile phase, two peaks were observed that were well-resolved from each other (figure 1d). We named these two peaks as isomer $\mathrm{X}$ and
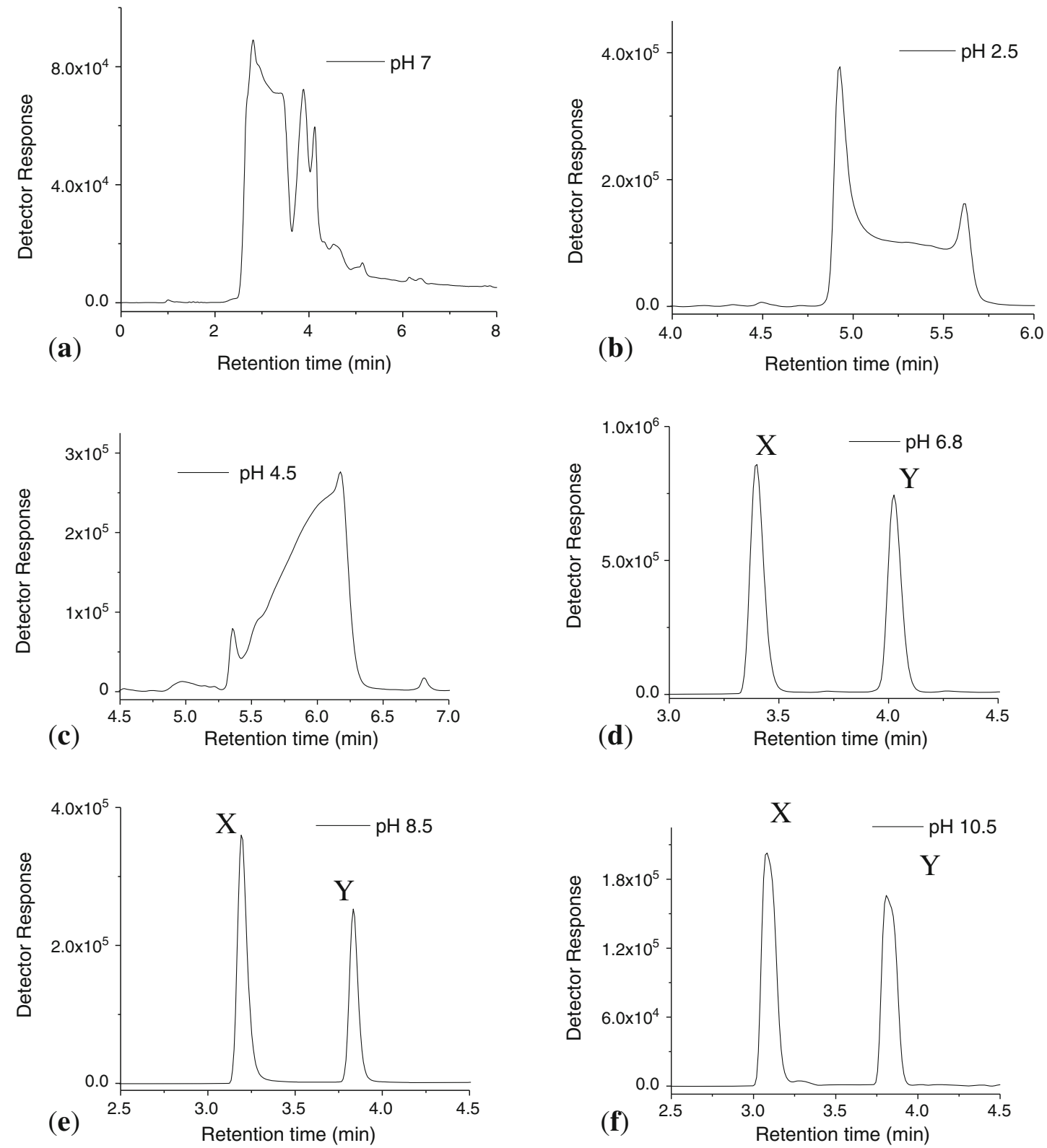

Figure 1. HPLC chromatogram of Lwox ligand; (a) in neutral pH, (b) $\mathrm{pH} 2.5$, (c) $\mathrm{pH} 4.5$, (d) $\mathrm{pH} 6.8$, (e) $\mathrm{pH} 8.5$ and (f) $\mathrm{pH} 10.5$. 
Table 1. Chromatographic data for peaks observed in figure 1e and $\mathrm{f}$ at $254 \mathrm{~nm}$.

\begin{tabular}{lcccc}
\hline $\mathrm{pH}$ & Peak & Ret. time (in min.) & \% Area & Peak purity index \\
\hline 8.5 & $\mathrm{X}$ & 3.426 & 57.198 & 0.997 \\
& $\mathrm{Y}$ & 4.073 & 42.802 & 0.998 \\
10.5 & $\mathrm{X}$ & 3.079 & 53.792 & 1.000 \\
& $\mathrm{Y}$ & 3.805 & 45.104 & 0.999 \\
Isocratic & $\mathrm{X}$ & 2.612 & 53.865 & 1.000 \\
& $\mathrm{Y}$ & 4.200 & 46.135 & 1.000 \\
\hline
\end{tabular}

isomer Y (the peak with less retention time is named as isomer $\mathrm{X}$ and the other with more retention time is named $\mathrm{Y}$ isomer). The separation between the isomer X (Rt-3.392 min) and isomer Y (Rt-4.020 min) is observed to be $\sim 0.628 \mathrm{~min}$ and isomer $\mathrm{X}$ is present in more quantity than $\mathrm{Y}$ (table S1). The peak purity index has been found to be 0.99 for both the isomer; hence there is no merged impurity in both isomers. (iv) At $\mathrm{pH} 8.5$ pattern of chromatogram (figure 1e) is similar to that of pattern observed at $\mathrm{pH} 6.8$ but the separation of isomers at this $\mathrm{pH}$ of mobile phase is much higher ( $\sim 0.647 \mathrm{~min}$.) as compared to $\mathrm{pH} 6.8$ (table 1 ). Peak purity index of both the isomer is 0.99 ; hence there is no merged impurity. Tailing factor of isomer $\mathrm{X}$ and isomer $\mathrm{Y}$ is 1.426 and 1.201 , respectively, thus the peak shape of isomer $\mathrm{X}$ is less symmetric than the isomer Y. (v) At pH 10.5 of mobile phase, two peaks of isomers/tautomers (figure 1f, table 1)
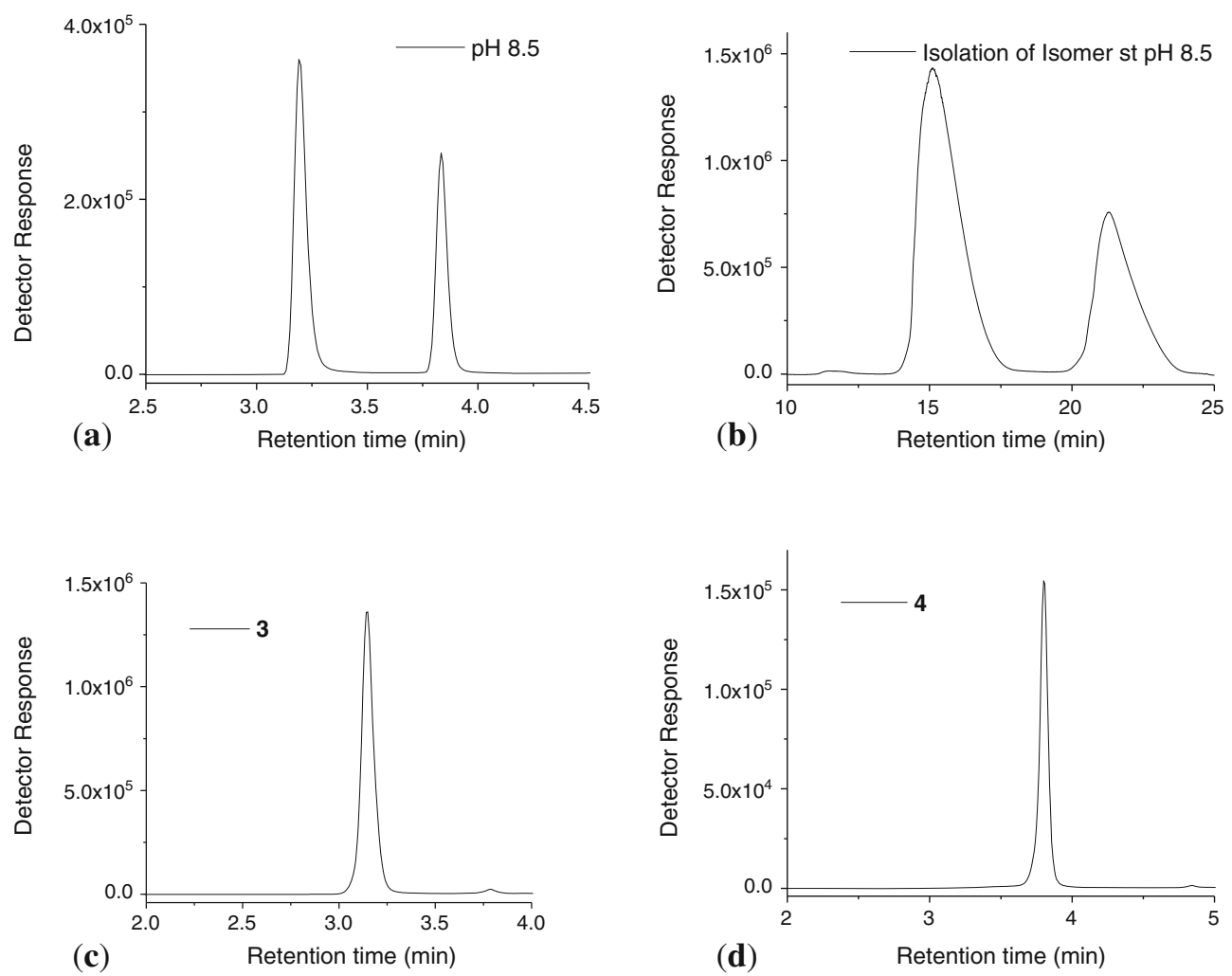

Figure 2. (a) Chromatogram obtained before isolation of isomers at pH 8.5. (b) Chromatogram obtained for isolation of isomers at $\mathrm{pH} 8.5$ on preparative HPLC. (c) Chromatogram of isomer $\mathbf{3}$ after isolation. (d) Chromatogram of isomer $\mathbf{4}$ after isolation. 
were observed with a separation between the peak $\mathrm{X}$ (Rt-3.079) and peak Y (Rt-3.805) is $0.72 \mathrm{~min}$. This chromatographic condition is suitable for separation of isomers/tautomers. (vi) Two distinct peaks are observed in isocratic elution. The better resolution is observed of tautomers in isocratic elution in comparison to gradient elution (figure S1). Peak shape is sharp in isomer $\mathrm{X}$ compared to isomer $\mathrm{Y}$. The peak shape of isomer $\mathrm{Y}$ is broad due to intermolecular or intramolecular hydrogen bonding effects of the carbonyl oxygen's or the hydroxyl group. ${ }^{10,11}$ Peak shape of $\mathrm{X}$ (tailing factor $\sim 1$ ) isomer was found to be more symmetric than isomer $\mathrm{Y}$ (tailing factor $\sim 0.88$ ). Abundance of isomer $\mathrm{X}$ is more than isomer $\mathrm{Y}$ in isocratic elution (table 1).

When syn, anti and amphi isomers, ${ }^{9}$ are present in the solution of Lwox, several peaks are expected ${ }^{27}$ in the chromatogram. However, only two peaks are observed at $\mathrm{pH} 6.8,8.5$ and 10.5. The peak shape for all $\mathrm{pH}$
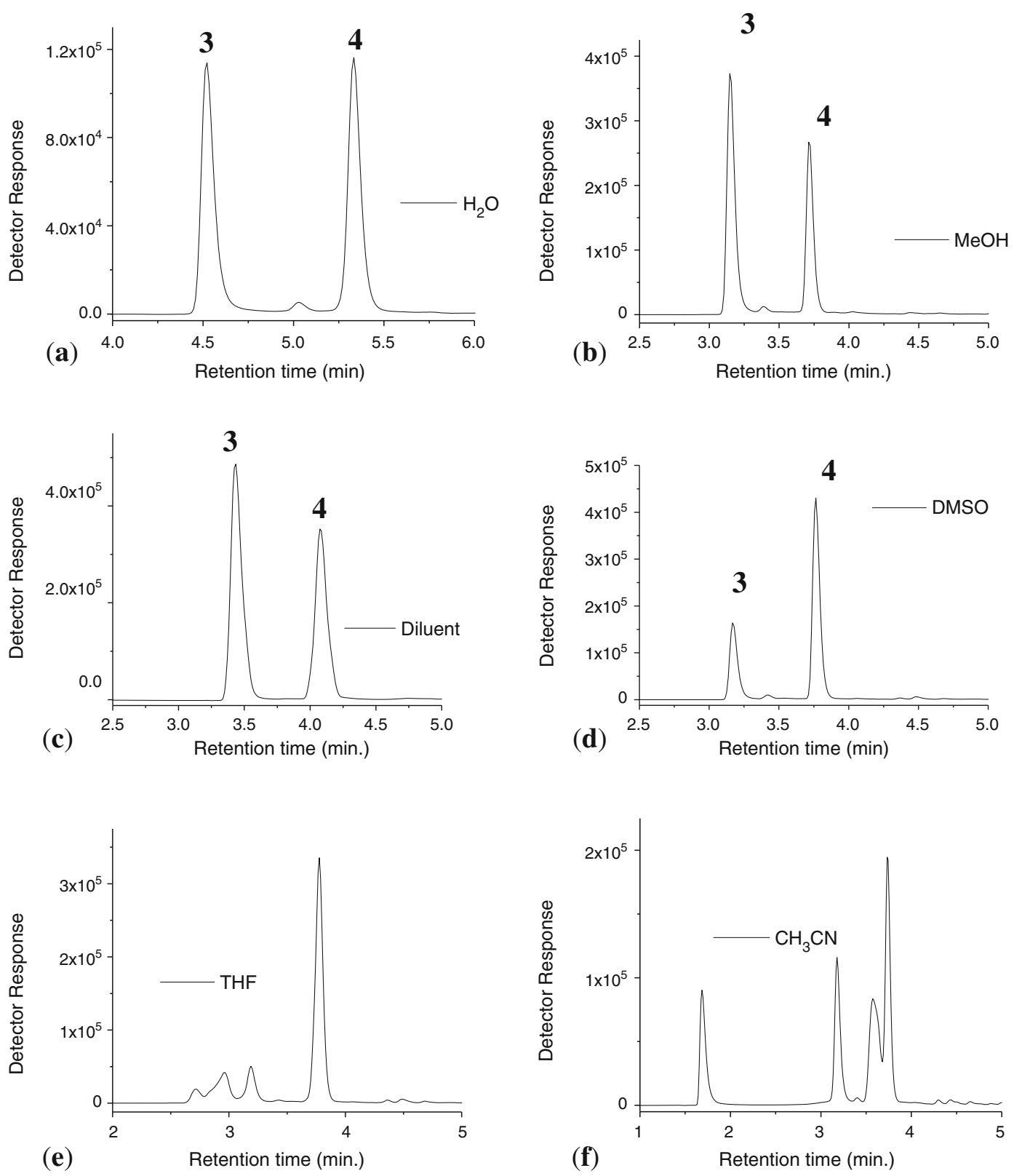

Figure 3. Effect of solvent on retention and separation of isomers of Lwox; (a) $\mathrm{H}_{2} \mathrm{O},(\mathbf{b}) \mathrm{CH}_{3} \mathrm{OH}$, (c) $\mathrm{CH}_{3} \mathrm{CN}$, (d) THF, (e) diluent, and (f) DMSO. 
range (except $\mathrm{pH} 7$ ) was observed to be good. The separation in neutral buffer and basic buffer $\mathrm{pH}$ range is observed to be base to base, however in acidic $\mathrm{pH}$ range there is no base to base separation of the peaks and the nature of the chromatogram observed at $\mathrm{pH}$ 2.5 and 4.5 is similar to equillibria found for keto-enol oxime tautomers. ${ }^{26}$ Further, the spectroscopic methods like FT-IR and UV-Visible spectra clearly indicated the presence of ortho and para tautomers ${ }^{14}$ of Lwox at $\mathrm{pH}$ 6.8, 8.5 and 10.5. Hydroxy naphthoquinones are known to exist in ortho and para tautomeric forms. ${ }^{28,29}$ Peak Y retains longer time on the column, due to the presence of hydrogen bonding effects and polarity, this peak has been assigned to ortho i.e., tautomer 4; (4-hydroxy2-naphthoquinone-1-oxime), while peak $\mathrm{X}$ has been assigned for para i.e., tautomer $\mathbf{3}$ (scheme 2). The tautomer 3; (2-hydroxy-4-naphthoquinone-1-oxime) is stabilized by strong intramolecular hydrogen bonding hence will not adsorbed strongly on the column and will be eluted before tautomer 4 .

\subsection{Reversed phase chromatographic isolation of tautomers of Lwox}

The chromatogram obtained before isolating the isomers is shown in figure $2 \mathrm{a}$. The $\%$ of tautomer $\mathbf{3}$ have been observed ( $\mathrm{Rt}=3.140 \mathrm{~min})$ to be more than tautomer $4(\mathrm{Rt}=3.799 \mathrm{~min})$. The already developed method $\mathrm{V}$ has been scale up on preparative HPLC for the isolation of tautomers, the obtained chromatogram of isolation of tautomers is shown in figure $2 \mathrm{~b}$. Further details used are mentioned in method VIII. The tautomer 3 (figure 2c) has been eluted at $\mathrm{Rt}=15.09 \mathrm{~min}$. and tautomer 4 (figure $2 \mathrm{~d}$ ) eluted at $\mathrm{Rt}=21.27 \mathrm{~min}$.

\subsection{Purity of tautomer 3 and 4 after isolation}

A solid of tautomer 3 was obtained after lyophilisation, at low temperature with purity of isolated solid $\mathbf{3}$ determined to be $98.5 \%$ by LC-MS analysis (figure S2). The chromatogram also shows $\sim 1.5 \%$ tautomer 4 . The percentage of tautomer 4 increases with time in solvent. The solid of $\mathbf{4}$ have been obtained after lyophilisation and contains ammonium bicarbonate that is $99.9 \%$ pure.

\subsection{LC-MS analysis of Lwox and isolated tautomers 3 and 4}

The tautomer has been confirmed by LC-MS analysis (figure S2). While chromatographic methods I, II, III are not suitable for separation of isomers, methods IV, V and VI are suitable for analysis; however in method IV and V, the peak shape is broad and separation between the peaks is less as compared to method VI. Thus, method IV and V are excluded. The method VI is suitable for LC-MS analysis of tautomers.

The molecular weight of Lwox is $189.17 \mathrm{~g} \mathrm{~mol}^{-1}$ and experimentally it was determined to be $190[\mathrm{M}+$ 1] by using positive polarity and ESI probe (source for ionization). There is a presence of tautomer $4, \sim 13 \%$ in isolated solid of $\mathbf{3}$. The presence of tautomer $\mathbf{4}$ is due to interconversion of tautomer $\mathbf{3}$ during the course of analysis. The purity of tautomer $\mathbf{4}$ was found to be $\sim 95 \%$.

Table 2. Chromatographic data for peaks observed in figure 3 at $254 \mathrm{~nm}$.

\begin{tabular}{|c|c|c|c|c|c|}
\hline Sl. No. & Solvent & Ret. time (in min.) & $\%$ Area & Peak purity index & Tailing factor \\
\hline \multirow[t]{2}{*}{1.} & $\mathrm{H}_{2} \mathrm{O}$ & 4.515 & 50.58 & 0.999 & 1.61 \\
\hline & & 5.327 & 49.42 & 0.999 & 1.30 \\
\hline \multirow[t]{2}{*}{2.} & $\mathrm{CH}_{3} \mathrm{OH}$ & 3.145 & 61.35 & 0.999 & 1.55 \\
\hline & & 3.711 & 38.65 & 0.999 & 1.49 \\
\hline \multirow[t]{2}{*}{3.} & Diluent & 4.727 & 47.19 & 1.000 & 1.59 \\
\hline & & 5.552 & 52.81 & 1.000 & 1.31 \\
\hline \multirow[t]{2}{*}{4.} & DMSO & 3.165 & 29.69 & 0.999 & 1.56 \\
\hline & & 3.758 & 70.31 & 1.000 & 1.49 \\
\hline \multirow[t]{4}{*}{5.} & THF & 2.710 & 04.49 & 1.000 & - \\
\hline & & 2.957 & 15.59 & 0.999 & - \\
\hline & & 3.184 & 11.30 & 0.999 & - \\
\hline & & 3.770 & 68.68 & 1.000 & 1.08 \\
\hline \multirow[t]{4}{*}{6.} & $\mathrm{CH}_{3} \mathrm{CN}$ & 1.681 & 18.49 & 0.956 & 2.05 \\
\hline & & 3.174 & 21.39 & 0.999 & 1.43 \\
\hline & & 3.571 & 26.55 & 0.998 & - \\
\hline & & 3.733 & 33.57 & 0.997 & - \\
\hline
\end{tabular}




\subsection{FT-IR spectra of Lwox and isolated tautomer 3 and 4}

The isolated tautomers $\mathbf{3}$ and $\mathbf{4}$ show vibration peaks for ammonium bicarbonate in FT-IR spectrum (figure S3). The vibrational frequency at $1519 \mathrm{~cm}^{-1}$ has been assigned to ammonium bicarbonate. The other vibrations of ammonium bicarbonate merged in strong absorption of Lwox tautomers. The nature of the FTIR spectrum varies between 3600 and $2500 \mathrm{~cm}^{-1}$ for 3 and 4 (figure $\mathrm{S} 3 \mathrm{a}$ ). $v_{\mathrm{C}=\mathrm{O}}$ and $v_{\mathrm{C}=\mathrm{N}}$ vibrations are observed at $1707 \mathrm{~cm}^{-1}$ and $1585 \mathrm{~cm}^{-1}$, respectively in 3 . A paranaphthoquinone (p-NQ) vibration are observed at $1280 \mathrm{~cm}^{-1}$ and $1263 \mathrm{~cm}^{-1}$ in $\mathbf{3}$ as expected these frequency were absent in 4 , instead a broad band centred at $\sim 1246 \mathrm{~cm}^{-1}$ is observed.

\subsection{UV-visible spectra of isolated tautomer $\mathbf{3}$ and $\mathbf{4}$}

The colour of isolated tautomers was red-orange for tautomer 3 and yellow for tautomer 4. UV-visible
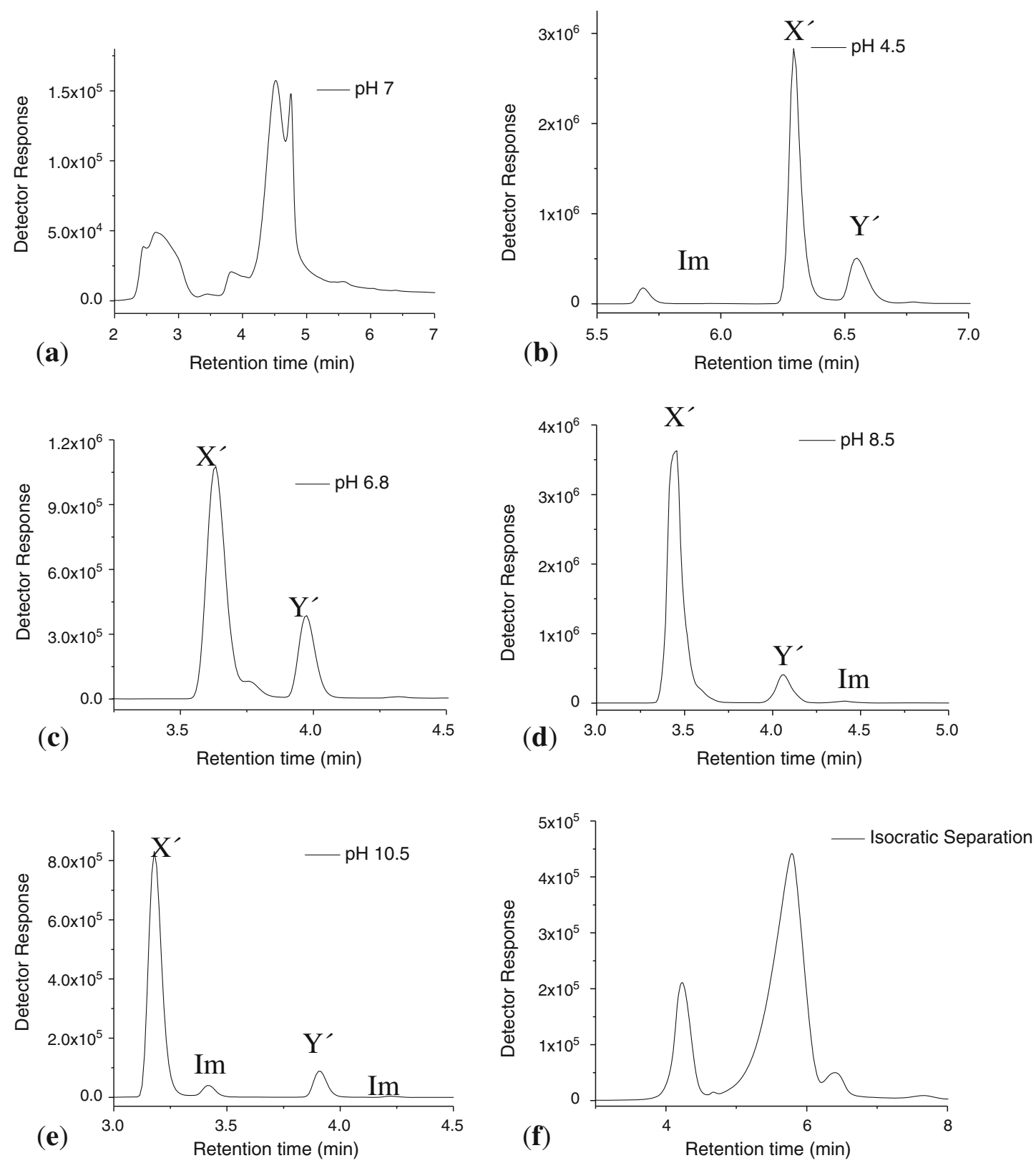

Figure 4. HPLC chromatogram of Phox; (a) at neutral pH, (b) $\mathrm{pH} 4.5$, (c) $\mathrm{pH} 6.8$, (d) $\mathrm{pH} 8.5$, (e) $\mathrm{pH}$ 10.5 , and (f) isocratic elution. 
spectra (figure S4) of $\mathbf{3}$ shows peaks at 212, 247.5, $262.1,319.1 \mathrm{~nm}$ in UV region and a peak at $420 \mathrm{~nm}$ in visible region, while 4 shows peaks at $216.4,263.8$, $290.8,333.8$ and $389.8 \mathrm{~nm}$ in UV region and $405 \mathrm{~nm}$ in visible region. The peaks in UV region are assigned to $\pi-\pi *$ transition of the quinonoid and benzenoid rings, and a peak in visible region was classified as a charge transfer transition for in tautomer $\mathbf{3}$ and $\mathbf{4}$.
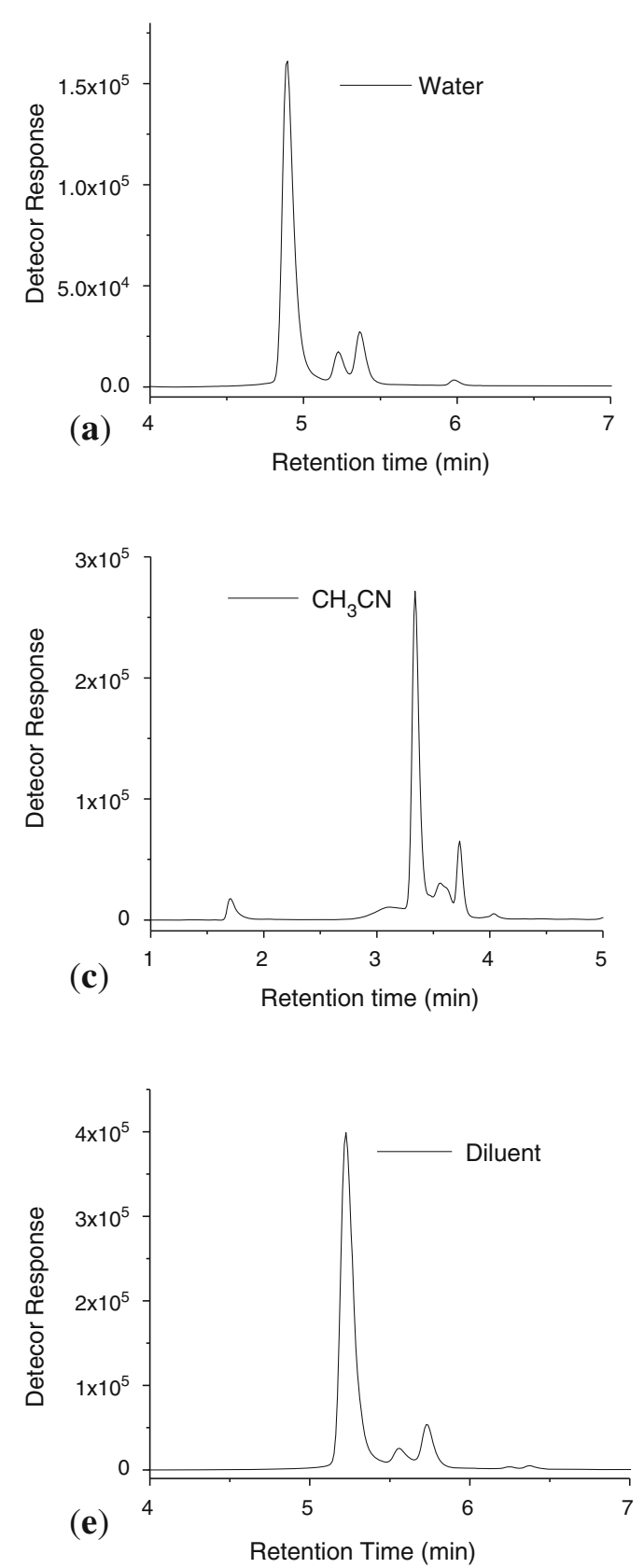

3.7 Effect of solvent polarity on separation of the isomers/tautomers of Lwox

Composition of tautomers varies with polarity of the solvents where as composition of stereoisomer's remains the same. The solution of Lwox has been prepared in various solvents viz $\mathrm{H}_{2} \mathrm{O}$, diluent, DMSO, $\mathrm{CH}_{3} \mathrm{OH}$, THF and $\mathrm{CH}_{3} \mathrm{CN}$. Neutral chromatographic
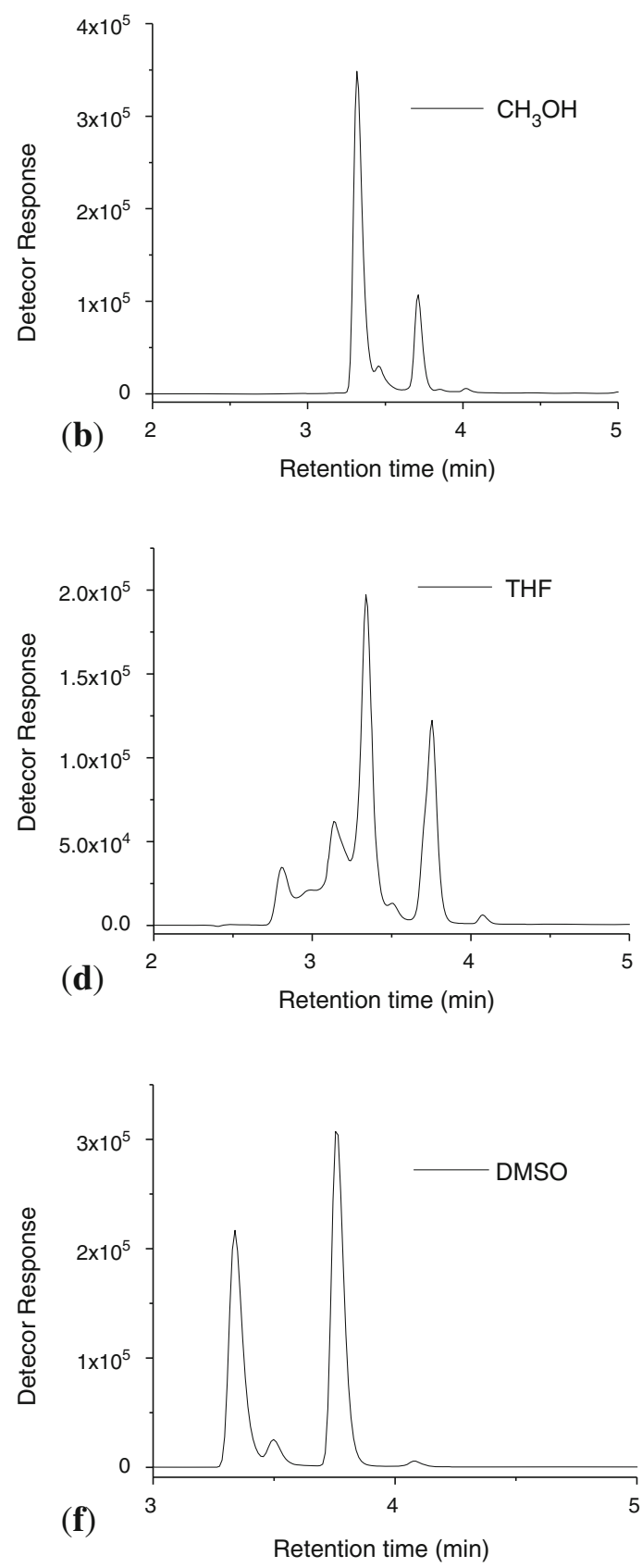

Figure 5. Effect of solvent on retention and separation of isomers of Phox; (a) $\mathrm{H}_{2} \mathrm{O}$, (b) $\mathrm{CH}_{3} \mathrm{OH}$, (c) $\mathrm{CH}_{3} \mathrm{CN}$, (d) THF, (e) diluent, and (f) DMSO. 
conditions (method IV) have been used and chromatograms obtained are shown in figure 3. Retention time and the percentage of isomers depends on the observed as $\sim 50: 50$ in water and diluent, this may be due to nearly same stability of both isomers in water, $\sim 60: 40$ in methanol and $~ 30: 70$ in DMSO. Peak purity index observed to be $\sim 1$ hence there is no merged impurity in both the peaks. More than two peaks are observed in chromatograms of THF and $\mathrm{CH}_{3} \mathrm{CN}$ solvents, this may be due to the instability of tautomers in these solvents or presence of syn and anti stereoisomer's. Thus, separation of Lwox in various solvent gives us an idea about the presence of tautomers instead of stereoisomers (table 2).

\subsection{Separation}

of 2-hydroxy-3-methy-4-naphthoquinone-1-oxime

(Phox) isomers

Separation of Phox isomers have been attempted in various $\mathrm{pH}$ of the mobile phase. The desired $\mathrm{pH}$ is achieved using appropriate buffer solutions. Figure 4 shows chromatogram for Phox separation obtained at $\mathrm{pH} 7,4.5$, $6.8,8.5,10.5$ and isocratic separation and chromatographic data are presented in table S2.

(i) At $\mathrm{pH} 7$ (without modifier) Phox retain on column and there is no interaction of Phox with mobile phase and no separation of the peaks are observed. (ii) At $\mathrm{pH}$ 2.5 (figure S5), there are three peaks were observed, two peaks are of isomers at Rt-5.570 min and Rt-5.804 min with mass $204(M+1)$ and a peak due to impurity with $m / z 201[\mathrm{M}+1]$. The percentage of impurity is significantly less. The separation of isomer is not base to base, however the impurity is well-separated from the desired isomers. (iii) At pH 4.5, resolution between isomers is observed, however there is no base to base separation. Three peaks are observed, two of the peaks belong to isomers while one peak due to impurity. The unequal concentration of isomers is observed at this $\mathrm{pH}$. Phox retains on column. (iv) At $\mathrm{pH}$ 6.8, the impurity peak (Rt-3.750 min) is merged in isomer $\mathrm{X}^{\prime}$ (Rt-3.968) and there is no separation between the isomers. (v) At $\mathrm{pH}$ 8.5 , separation between the isomer peaks is $0.6 \mathrm{~min}$.

Table 3. Chromatographic data obtained of peaks of figure $5 \mathrm{a}-\mathrm{f}$ at $254 \mathrm{~nm}$.

\begin{tabular}{|c|c|c|c|c|c|}
\hline Sl. No. & Solvent & Ret. time (in min) & $\%$ Area & Peak purity index & Tailing factor \\
\hline \multirow[t]{4}{*}{1.} & \multirow[t]{4}{*}{$\mathrm{H}_{2} \mathrm{O}$} & 4.887 & 84.27 & 1.000 & 1.64 \\
\hline & & 5.222 & 04.99 & 1.000 & 1.16 \\
\hline & & 5.362 & 09.43 & 0.990 & 1.44 \\
\hline & & 5.974 & 01.11 & 0.999 & 1.37 \\
\hline \multirow[t]{4}{*}{2.} & \multirow[t]{4}{*}{$\mathrm{CH}_{3} \mathrm{OH}$} & 3.314 & 74.54 & 0.949 & 1.47 \\
\hline & & 3.453 & 01.27 & 0.591 & 1.60 \\
\hline & & 3.705 & 21.11 & 0.999 & 1.37 \\
\hline & & 4.014 & 00.72 & 0.999 & 1.48 \\
\hline \multirow[t]{4}{*}{3.} & \multirow[t]{4}{*}{ Diluent } & 5.220 & 88.68 & 1.000 & 1.59 \\
\hline & & 5.552 & 02.67 & 0.974 & 1.33 \\
\hline & & 5.726 & 08.07 & 1.000 & 1.44 \\
\hline & & 6.367 & 00.56 & 0.999 & 1.51 \\
\hline \multirow[t]{4}{*}{4.} & \multirow[t]{4}{*}{ DMSO } & 3.333 & 41.51 & 0.968 & 1.66 \\
\hline & & 3.493 & 04.50 & 0.977 & - \\
\hline & & 3.754 & 53.14 & 0.999 & 1.52 \\
\hline & & 4.075 & 00.84 & 0.999 & 1.19 \\
\hline \multirow[t]{7}{*}{5.} & \multirow[t]{7}{*}{ THF } & 2.804 & 07.44 & 1.000 & - \\
\hline & & 2.984 & 06.65 & 0.992 & - \\
\hline & & 3.135 & 18.99 & 0.999 & - \\
\hline & & 3.335 & 41.04 & 0.939 & - \\
\hline & & 3.498 & 01.45 & 0.990 & - \\
\hline & & 3.748 & 23.65 & 1.000 & 0.98 \\
\hline & & 4.069 & 00.75 & 1.000 & 1.38 \\
\hline \multirow[t]{6}{*}{6.} & \multirow[t]{6}{*}{$\mathrm{CH}_{3} \mathrm{CN}$} & 1.699 & 04.61 & 0.143 & - \\
\hline & & 3.105 & 7.560 & 0.945 & - \\
\hline & & 3.334 & 62.53 & 0.694 & - \\
\hline & & 3.556 & 12.80 & 0.793 & - \\
\hline & & 3.727 & 11.62 & 0.472 & - \\
\hline & & 4.031 & 00.86 & 1.000 & - \\
\hline
\end{tabular}


Table 4. Effect of treatment of $\mathbf{3}$ and $\mathbf{4}$ in three different cell lines.

\begin{tabular}{lllc}
\hline & COLO 205 & U87 MG & MIA PaCa-2 \\
\hline $\mathbf{3}$ & Resistant & Inactive & Inactive \\
$\mathbf{4}$ & Resistant & Inactive & Inactive \\
\hline
\end{tabular}

Isomer $\mathrm{X}^{\prime}$ (Rt-3.443 min) shows a tailing effect, which presumably arises from a merged impurity (tailing factor 0.953). An impurity peak is observed (Im) at (Rt-4.397 min), it is separated from isomer $\mathrm{Y}^{\prime}$. (vi) At $\mathrm{pH} 10.5$, four peaks are observed. Two peaks belong to impurity. Impurity peaks are confirmed by LC-MS analysis with $\mathrm{m} / \mathrm{z} 201[\mathrm{M}+1]$. (vii) Broad peaks are observed in isocratic elution, thus the isocratic elution is not suitable for the separation and elution of isomers.

\subsection{Effect of solvent polarity on separation of the isomers of Phox}

A neutral chromatographic condition (method IV) is used for the study of the effect of solvent on the separation of isomers/tautomers of Phox. Retention time and the percentage of isomer depend upon the polarity of the solvents as shown in figure 5a-f; the chromatographic data is presented in table 3 . Four peaks are observed in water, methanol and diluent solvents, the percentage of isomer $\mathrm{X}^{\prime}$ is more than the isomer $\mathrm{Y}^{\prime}$, however the percentages of isomers varies with solvent polarity. In polar protic solvent, the isomers retained on the column may be due to 'inter' or 'intra' molecular hydrogen bonding. But the peaks were not separated base to base in DMSO, THF and $\mathrm{CH}_{3} \mathrm{CN}$ solvent; hence these solvents are not suitable for the elution of Phox.

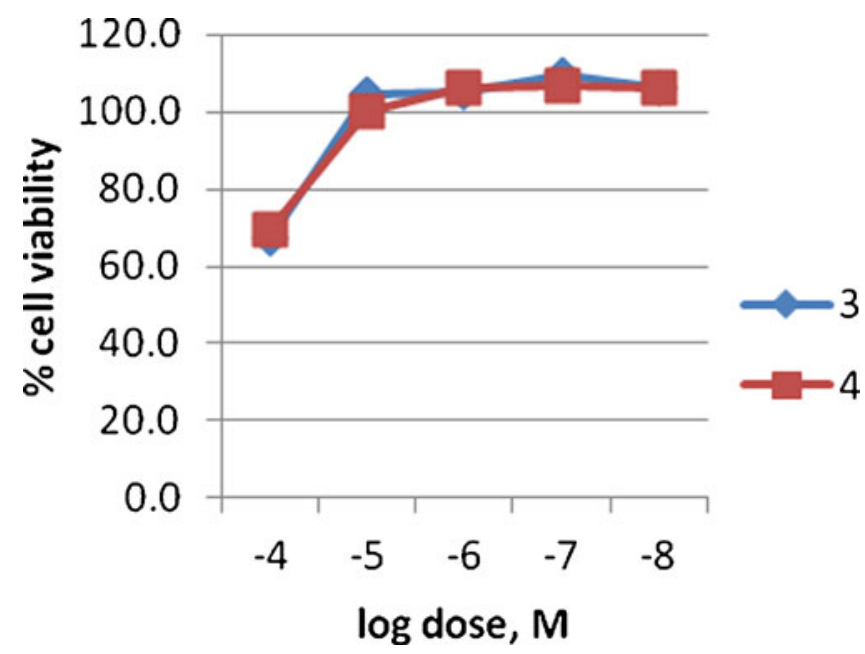

Figure 6. Dose-response curve upon treatment of COLO 205 cell line with $\mathbf{3}$ and $\mathbf{4}$.
3.10 In vitro cell viability assay of tautomers 3 and 4 of Lwox

Cell viability studies on three cancer cell lines of different tissue origin upon treatment with $\mathbf{3}$ and $\mathbf{4}$ at varying concentration using XTT assay were studied. From the results it was observed that tautomers 3 and $\mathbf{4}$ were inactive in cell lines (table 4) U87 MG and MIA PaCa-2 at concentration $>10 \mathrm{mM}$. COLO 205 cell line treated with $10 \mathrm{mM}$ concentration of compounds resulted in $67 \%$ and $69 \%$ of viable cells (figure 6). However, doxorubicin was active in all $\mathbf{3}$ cell lines with an $\mathrm{IC}_{50}$ value of $0.68 \mathrm{nM}, 0.34 \mu \mathrm{M}$ and $0.1 \mathrm{nM}$ in COLO 205, U87 MG and MIA PaCa-2 cell lines, respectively (figure 7).

\subsection{DFT calculations}

Geometry-optimized structures for tautomers $\mathbf{3}$ and $\mathbf{4}$ ( $3^{\prime}$ and $4^{\prime}$ in Phox) were computed using the B3LYP method. The optimized structures are presented in figure 8 for Lwox tautomers and in figure 9 for Phox tautomers. Structures $\mathbf{3}$ and $\mathbf{3}^{\prime}$ are 4.7 and $5.8 \mathrm{kcal} \mathrm{mol}^{-1}$ more stabilized than $\mathbf{4}$ and $\mathbf{4}^{\prime}$, respectively, as a result of a hydrogen bonding interaction between the 2-hydroxyl group and the nitrogen of the oxime. This affords the favourable amphi disposition of the $\mathrm{N}-\mathrm{OH}$ group leading to a short contact of $2.131 \AA$ in Lwox and $2.129 \AA$ in Phox with nearby $\mathrm{H}(8)$ of the aromatic ring. The $\mathrm{C}(1)-$ $\mathrm{N}(1)$ and $\mathrm{C}(4)-\mathrm{O}(4)$ distances of $1.290 \AA$ and $1.235 \AA$ in Lwox, and 1.290 $\AA$ and $1.234 \AA$ in Phox, respectively are in the range for a double bond; the $\mathrm{C}(2)-\mathrm{O}(2)$ distance of $1.338 \AA$ and $1.342 \AA$ in Lwox and Phox is consistent with single bond. Swapping the hydroxyl and ketyl groups in $\mathbf{4}$ results in a slight shortening of the $\mathrm{N}-\mathrm{O} \cdots \mathrm{H}(8)$ interaction by $\sim 0.04 \AA$ concomitant

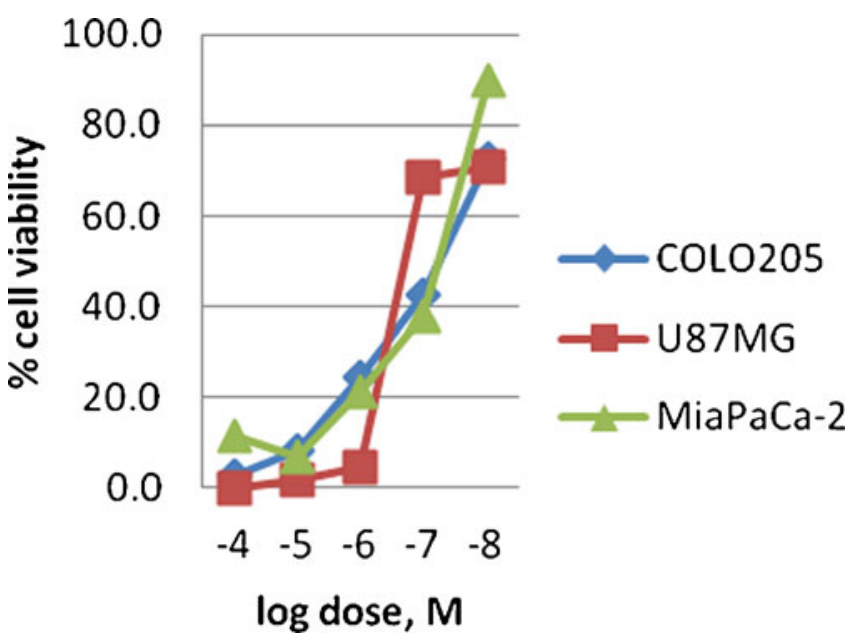

Figure 7. Dose-response curve upon treatment with doxorubicin in all three cell lines (COLO 205, U87 MG and MIA $\mathrm{PaCa}-2)$. 


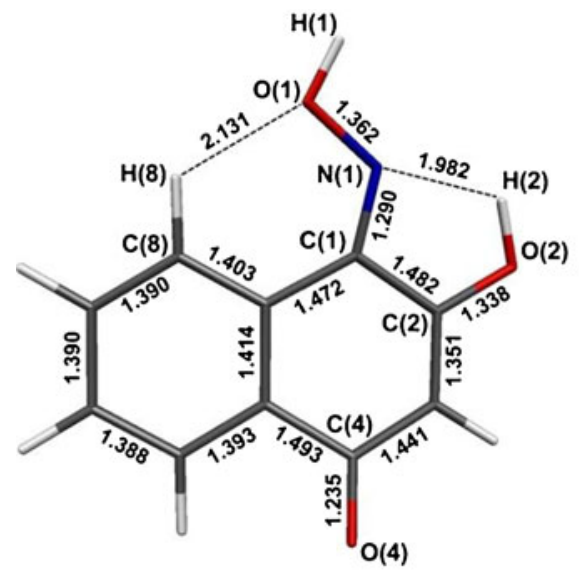

3

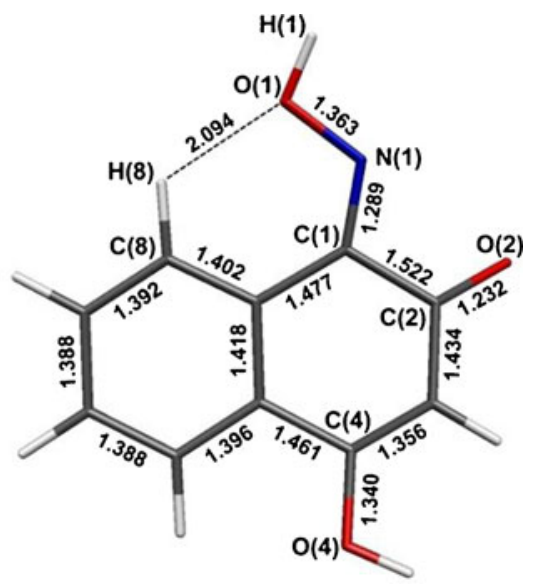

4

Figure 8. Geometry optimized structures for $\mathbf{3}$ and $\mathbf{4}$ from B3LYP-DFT calculations. Indicated distances are in $\AA$.

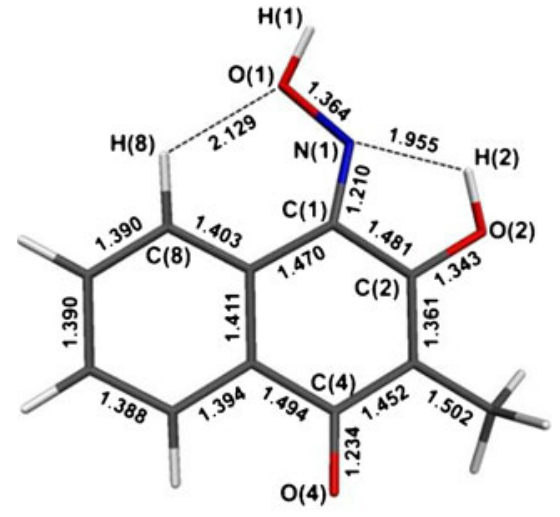

3'

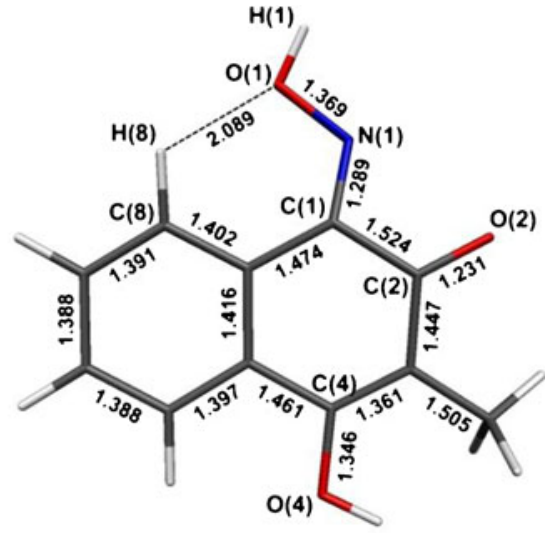

$4^{\prime}$

Figure 9. Geometry optimized structures for $\mathbf{3}^{\prime}$ and $\mathbf{4}^{\prime}$ from B3LYP-DFT calculations. Indicated distances are in $\AA$.

with the absence of any intramolecular hydrogen bonding with the oxime nitrogen atom, no energy regained via new interactions with the 4-hydroxyl substituent due to the absence of suitable donor groups in its vicinity.

\section{Conclusions}

The separation, isolation and characterization of tautomers of naphthoquinoneoxime have been carried out for the first time. The influence of $\mathrm{pH}$ on the mobile phase has been studied on the separation of isomers of 2-hydroxy-4-naphthoquinone-1-oxime; Lwox and 3-methyl-2-hydroxy-4-naphthoquinone-1oxime; Phox. The $\mathrm{pH}$ has been maintained using various buffer solutions in water. Two distinct peaks are observed in $\mathrm{pH}$ range studied between $\mathrm{pH} 2.5$ and 10.5 for Lwox. Tautomeric equilibrium has been observed in acidic $\mathrm{pH}$ of mobile phase, while base to base separation of the isomers is present at neutral and basic $\mathrm{pH}$ of mobile phase in Lwox. Tautomers 3 (2-hydroxy-4-naphthoquinone-1-oxime) and 4 (4-hydroxy-2-naphthoquinone-1-oxime) are isolated in solid state by preparative HPLC technique and are characterized by LC-MS, FT-IR, and UV-visible spectra. Tautomers $\mathbf{3}$ and $\mathbf{4}$ are stable in solid state, while their fast interconversion to one another is observed in solution. FT-IR spectra of $\mathbf{3}$ show distinct paranaphthoquinone frequency at $\sim 1280-1290 \mathrm{~cm}^{-1}$, this frequency is absent in 4. Charge transfer bands are observed in UV-visible spectra at $420 \mathrm{~nm}$ and $405 \mathrm{~nm}$ for red orange, $\mathbf{3}$ and yellow, 4 , respectively.

Separation of isomers/tautomers of Phox cannot be achieved either by chromatographic methods used nor 
by varying polarity of solvents. There could be two reasons for the same, (a) chromatographic conditions are inadequate for separation and (b) presence of stereoisomers such as syn and anti as well as ortho and para tautomers present in solution.

Cell viability studies on three cell lines showed that 3 and 4 were inactive in both U87MG (glioblastoma astrocytoma) and MIAPaCa-2 (human pancreatic carcinoma) cancer cell lines some degree of sensitization was observed in COLO205 (human colorectal adenocarcinoma). In the contrary, doxorubicin, which was used as a positive control was very active in all tissue types at a nanomolar range. From these studies it may be concluded that $\mathbf{3}$ and $\mathbf{4}$ can be used as potential lead compounds to specifically target against colon carcinoma without cross reactivity against any other vital tissues.

Geometry-optimized structures for tautomers $\mathbf{3}$ and 4 ( $3^{\prime}$ and $4^{\prime}$ in Phox) were computed using the B3LYP method. Structures $\mathbf{3}$ and $\mathbf{3}^{\prime}$ are 4.7 and $5.8 \mathrm{kcal} \mathrm{mol}^{-1}$ more stabilized than $\mathbf{4}$ and $\mathbf{4}^{\prime}$, respectively, as a result of a hydrogen bond interaction between the 2-hydroxyl group and the nitrogen of the oxime.

\section{Supplementary information}

Details of experimental conditions for separation of isomers by HPLC, methods I to IX, figures S1-S5 and tables $\mathrm{S} 1$ and $\mathrm{S} 2$ can be seen at www.ias.ac.in/chemsci website as supplementary information.

\section{Acknowledgements}

This work was supported through grants from the Board for College and University Education (BCUD), University of Pune and Rapid Grant for Young Investigators RGYI scheme of Department of Biotechnology (DBT), Government of India (Ref. No. BT/PR6565/GBD/27/456/2012).

\section{References}

1. Kržan A, Crist D R and Horák V 2000 J. Mol. Struct. $\mathbf{5 2 8} 237$

2. Ivanova G and Enchev V 2001 J. Chem. Phys. 264235
3. Buraway A, Cais M, Chamberlain J T, Liversedge F and Thomson A R 1955 J. Chem. Soc. 3727

4. Hadzi D 1956 J. Chem. Soc. 2725

5. Shono T, Hayashi Y and Shinra K 1971 Bull. Chem. Soc. Jpn. 443179

6. Herbison-Evans D and Richards R E 1964 Mol. Phys. 8 19

7. Saarinen H and Korvenranta J 1978 Finn. Chem. Lett. 7 233

8. Kržan A and Mavri J 2002 Chem. Phys. 27771

9. Rane S Y, Dhavale D D, Mulay M P and Khan E M 1990 Spectrochim. Acta 46A 113

10. Thube D R, Todkary A V, Joshi K A, Rane S Y, Gejji S P, Salunke S A, Marrot J and Varret F 2003 J. Mol. Struct. 622211

11. Zaware S B, Gonnade R G, Srinivas D, Khan A and Rane S Y 2011 New J. Chem. 51615

12. Joshi K A, Thube D R, Rane S Y and Gejji S P 2003 Theor. Chem. Acc. 110322

13. Rane S Y, Khan E M, Khursheed Ah and SalunkeGawali S 2005 Synth. React. Inorg. Met.-Org. and NanoMet.Chem. 5343

14. Anderson L C and Yanke R L 1934 J. Am. Chem. Soc. 56732

15. Marriott P, Trapp O, Shellie R and Schurig V $2001 J$. Chromatogr. A 919115

16. Marriott P, Aryusuk K, Shellie R, Ryan D, Krisnangkura $\mathrm{K}$, Schurig V and Trapp O 2004 J. Chromatogr. A 10 135

17. Perrin D D, Armarego W L and Perrin D R 1988 Purification of Laboratory Chemicals (Pergamon Press, London) p. 260

18. Fieser L F 1940 J. Biol. Chem. 1391

19. Konkimalla V B and Efferth T 2010 Biochem. Pharmacol. 151092

20. Neese F 2010 ORCA, an Ab initio, density functional and semiempirical electronic structure program package, version 2.8; Universität Bonn: Bonn, Germany

21. Lee C T, Yang W T and Parr R G 1988 Phys. Rev. B 7 785

22. Becke A D 1993 J. Chem. Phys. 985648

23. Klamt A and Schürmann G 1993 J. Chem. Soc., Perkin Trans. 2799

24. Schaefer A, Horn H and Ahlrichs R 1992 J. Chem. Phys. 972571

25. Weigend F and Ahlrichs R 2005 Phys. Chem. Chem. Phys. 73297

26. Chifuntwe C, Zhu F, Huegel H and Marriott P J $2010 \mathrm{~J}$. Chromatogr. A 12171114

27. Marcinkiewicz S and Green J 1963 J. Chromatogr. 10 366

28. Fieser L F 1926 J. Am. Chem. Soc. 482922

29. Rane S, Khursheed Ah and Gawali-Salunke S 2006 Syn. React. Inorg. Met. 6391 